\title{
Professional confidence in the roles as ambulance and medical incident commander
}

\author{
Michael Rosander and Jonson Carl-Oscar
}

Journal Article

Tweet

N.B.: When citing this work, cite the original article.

Original Publication:

Michael Rosander and Jonson Carl-Oscar, Professional confidence in the roles as ambulance and medical incident commander, Journal of Contingencies and Crisis Management, 2017. http://dx.doi.org/10.1111/1468-5973.12156

Copyright: Wiley: 24 months http://eu.wiley.com/WileyCDA/

Postprint available at: Linköping University Electronic Press

http://urn.kb.se/resolve?urn=urn:nbn:se:liu:diva-134156

LINKÖPINGS

UNIVERSITET 


\title{
Professional confidence in the roles as ambulance and medical incident commander
}

\author{
Michael ROSANDER, PhD, Associate Professor of Psychology ${ }^{1}$ \\ Carl-Oscar JONSON, $\mathrm{PhD}^{2}$
}

\begin{abstract}
The aim was to investigate professional confidence in the roles of ambulance and medical incident commander (AIC and MIC), and how it influences achievement of performance indicators at an incident site. A web-survey based on theoretical constructs (e.g. social identity, efficacy, accountability) and questions about prehospital emergency care connected to the roles were used $(n=426$ Swedish ambulance nurses and emergency medical technicians). The results showed that social identity, independence and occupation were moderators for professional confidence. Organisational support, relational trust, and independence were moderators for achieving performance indicators. Strengthening group identification and independence as MIC, and independence and support for women as AIC together with a stronger organisational support can increase professional confidence and improve performance.
\end{abstract}

${ }^{1}$ Department of Behavioural Sciences and Learning, Linköping University, Sweden

${ }^{2}$ Center for Disaster Medicine and Traumatology, and Department of Clinical and Experimental Medicine, Linköping University, Sweden

Corresponding author: Michael Rosander, $\mathrm{PhD}$, Associate Professor of Psychology, Department of Behavioural Sciences and Learning, Linköping University, 58183 Linköping, Sweden, Phone: +46 13-281000, E-mail: michael.rosander@liu.se, fax: +46 13-282145 


\section{Introduction}

Arriving at a major incident site as the first ambulance is a responsible task for an ambulance crew. A prerequisite for command involves sizing-up, assessing or evaluating the situation (Rimstad \& Braut, 2015) followed by an initiation of command and planning of the initial response (Lennquist, 2012; Nilsson \& Kristiansson, 2015). It is often an uncertain and unfamiliar situation, which requires an ability to cope with complexity - something that has been shown to be a challenge for ambulance crews (Bolling et al., 2007; Juffermans \& Bierens, 2010; Rüter, Örtenwall \& Vikström, 2007). Effective management is essential in minimising negative patient outcomes in major incidents (Aylwin et al., 2006; Sollid et al., 2012). Since 2005 Swedish regulations require that all ambulance crews should be able to initiate prehospital command and control when arriving first at the scene (The National Board of Health and Welfare, 2005, 2013). The confidence in dealing with this situation as well as the consequences for subsequent performance are the main focusses of this study.

\subsection{The roles of ambulance and medical incident commander}

The ambulance service in Sweden has gone from a relatively simple transport service for the sick and injured to today's more advanced medical care with a focus on diagnosis, care and treatment (Gårdelöv, 2016). This means that there are higher demands on the competence of the ambulance personnel. In Sweden there has been, since 2005, at least one registered nurse (often a specialised nurse) in each ambulance - most often in pair with one emergency medical technician (EMT) (The National Board of Health and Welfare, 2000, 2009; Gårdelöv, 2016). Regardless of specialization, a registered nurse working in the ambulance is hereafter referred to as an ambulance nurse or nurse. The Swedish ambulance service is governed by laws and guidelines from the National Board of Health and Welfare (2009). According to these, the ambulance service and the individual professional must act in accordance with science and best practice and can also be held accountable when deviating from these principles. The main responsibility for upholding this lies on the ambulance nurse. In the ambulance first at the incident site it is always a nurse that becomes responsible for the medical care - referred to as the medical incident commander (MIC) (The National Board of Health and Welfare, 2009; Suserud, 2005). The MIC is responsible for the medical perspective of the prehospital command such as directing care, triage and deciding on medical ambition of care. The other nurse, if there are two nurses in the first ambulance, or more often the EMT is given responsibility for overall management, communications and logistics as the designated ambulance incident commander (AIC). The AIC is responsible for the coordination of the ambulance resources at the incident site (Dolan \& Holt, 2013). Only an ambulance nurse can be MIC, but both the EMT and nurse can take on the role of AIC. A medical doctor arriving to the scene could assume the role of MIC, but normally acts as a consultant to the MIC and focuses on advanced medical care (National Board of Health and Welfare 2013; Nilsson \& Kristiansson, 2015).

The roles of ambulance nurses and EMTs have been described (e.g., Suserud, 2005; Suserud \& Haljamäe, 1997), but research on the roles of ambulance and medical incident commanders are scarce. As one aspect of the role, the ambulance incident commander is expected to function as a liaison toward police and rescue services. In this position there can be uncertainty, asymmetry and lack of incentive (Berlin \& Carlström, 2011) that can affect how one frames the professional role in terms of confidence. The lack of incentive in this context was explained as lack of motivation to collaborate based on, e.g., a fear of revealing lack of knowledge. Comfort (2007) also pointed to asymmetry in the information processes together with a degree of heterogeneity in experience, knowledge and capacity as aspects that can hinder communication processes and in turn can create uncertainty. Incidents will always 
have an element of uncertainty and the decision-making strategy will be influenced by the source of uncertainty (Elmqvist, Brunt, Fridlund \& Ekebergh, 2010; Rake \& Njå, 2009). Rake and Njå also highlighted skill acquisition in terms of Dreyfus and Dreyfus' (1986) model and the mindset of a competent performer involving acting in accordance with situational elements in a decision-making situation.

\subsection{Evaluation of performance}

There have been different attempts to measure or evaluate the work of ambulance and medical incident commanders, but there is no single agreed way to do this evaluation (Rimstad \& Braut, 2015). One way is to use performance indicators (Gryth et al., 2010; Lundberg, Jonsson, Vikström \& Rüters, 2008; Nilsson, Vikström \& Jonson, 2012; Rüter, 2006). Rüter and colleagues developed and tested 11 measurable performance indicators involving, for example, a first report within two minutes, formulating guidelines for the response within three minutes, and a second report within 10 minutes from arrival at the incident site (Lundberg et al., 2008; Rüter, 2006; Rüter \& Vikström, 2009; Rüter, Örtenwall \& Vikström, 2004). Training programmes in disaster medicine for nurses and doctors have been shown to increase self-efficacy (Smith, Farra, Dempsey \& Arms, 2015; Watters et al., 2015). Thus, self-efficacy could potentially be used as a measure of the level of preparedness for dealing with incidents and disasters.

\subsection{Aim}

The aim of the study was to investigate what creates professional confidence in the two roles of ambulance and medical incident commander, and how it influences achievement of performance indicators at an incident site.

\section{Theoretical framework}

The study is based on four main theoretical constructs: collective efficacy (Bandura, 1982), social identity (Tajfel \& Turner, 1979), trust (Simons \& Peterson, 2000), and accountability (Lerner \& Tetlock, 1999). The four concepts are linked and influence how ambulance and medical incident commanders interpret a situation, how they relate to others, as well as successful completion of the tasks at hand, and how they perceive confidence in their own roles.

Confidence or self-confidence is a person's belief in successful accomplishment of a specific task (Perry, 2012). Confidence in a professional setting relating to roles and demands of the occupation can be referred to as professional confidence (Holland, Middleton \& Uys, 2012; Ortiz, 2016) or professional role confidence (Cech, Rubineau, Silbey \& Seron, 2011). Professional confidence has been related to other similar concepts such as self-esteem and self-efficacy, as well as to professional identity (Bandura, 1982; Cech et al., 2012; Holland et al., 2012). Important aspects contributing to professional confidence are a working relationship with colleagues, and an organisation that is supportive and encourage selfreflection (Holland et al., 2012). Developing professional confidence for women in historically male dominated occupations often involves overcoming cultural biases which can reduce the level of confidence for women, at least initially (Cech et al., 2012).

Efficacy is a concept that can be applied to both an individual and a collective level. Selfefficacy is defined as confidence in the ability to perform a specific task (Bandura, 1982). Perceived collective efficacy is the equivalent concept on a group level - 'it will influence what people choose to do as a group, how much effort they put into it, and their staying power when group efforts fail to produce results' (143). Collective efficacy through social support in 
an important group (high group identification) can increase the possibility of such an outcome (Spears, 2010).

The degree to which a group becomes an important part of one's self-definition is also important for the adherence of relevant group norms (Livingstone, Haslam, Postmes \& Jetten, 2011). A self-definition in terms of important social groups can be understood from a social identity perspective (Haslam, 2004). Group influence on individual members and the members' compliance with group norms are influenced by degree of identification with the group (Leach et al., 2008). Group identification can be understood as one's psychological investment in a group together with a self-definition in part based on that group (Sani, 2012).

Intragroup trust is essential for group members to develop strong group identification. The level of intragroup trust is important for both emotional climate and group performance (Simons \& Peterson, 2000). It has been defined as a willingness to risk negative consequences by making oneself vulnerable, and to respond to another person's vulnerable position in a way that ensures a positive outcome (Johnson, Johnson \& Smith, 2007). Intragroup trust at a group level involves a generalised positive expectation for all members (Simons \& Peterson, 2000). This also reduces uncertainty about other group members' actions and how to relate to them (de Jong \& Elfring, 2010). Intragroup trust is also important when interpreting what group members communicate to each other - 'when group members do not trust each other, they are likely to interpret ambiguous behaviour of others negatively' (Simons \& Peterson, 2000: 104).

The final concept in focus is accountability. It 'refers to the implicit or explicit expectation that one may be called on to justify one's beliefs, feelings, and actions to others' (Lerner \& Tetlock, 1999: 255). The degree of identification with a group can increase accountability within the group (Rogers \& Lea, 2011). Cronin and Reicher (2009) studied police officers' behaviours and decision-making, and showed that individual accountability could have multiple audiences and that it sometimes involves contradictory demands. Kroon, van Kreveld and Rabbie (1991) showed that high accountability can result in a heightened selfawareness and a lowered ability to differentiate between out-groups. If a group perceives themselves to be responsible for the entire decision-making process and not just the end result, this is often followed by a greater need for information and increased frequency of repetition of the non-common information (Scholten, van Knippenberg, Nijstad \& de Dreu, 2007).

A number of studies have shown a positive connection between confidence in terms of self-efficacy and performance (Stajkovic \& Luthans, 1998). High self-efficacy have also been related to, e.g. increased aspiration and task persistence (Bandura, 1997). Performance indicators (Rüter et al., 2004) are judgements of efficacy in clearly defined tasks in a similar way as perceived self-efficacy is. In all self-estimates there are elements of self-deception, but in general, past research have shown significant and positive correlations between selfestimates of performance and actual performance albeit not as strong as one might expect (Ehrlinger \& Dunning, 2003). Mismatches between self-efficacy and actual performance can be related to the complexity of the task at hand (Stajkovic \& Luthans, 1998). This coincides with a cognitive bias called the Dunning-Kruger Effect (Dunning, 2011) in which people tend assess their abilities a higher than they really are - the less competent the more bias.

\section{Methods}

Data were collected via a web-survey between January-May and September-November 2014. The survey was developed for the study using the web survey tool Survey\&Report (Artologik, 
2015). It was based on theoretical constructs (e.g. social identity, efficacy, accountability, trust) as well as specific questions about prehospital emergency care connected to the two roles in focus for this study, ambulance and medical incident commander.

\subsection{Participants}

The participants of this study were emergency medical technicians and ambulance nurses from one county in Sweden. An email was sent to all ambulance personnel in the selected county - a total of 757 persons and 426 responses came in. There were 162 female and 264 male participants, and 116 were EMTs and 310 were ambulance nurses (44 nurses without specialisation, 175 specialised as ambulance nurses, and 91 with other specialist diploma). Work experience was divided in three equal groups using a percentile split: low experience, 0-6 years of work experience $(n=136)$, mid experience, $7-15$ years of work experience $(n=$ $158)$ and high experience, $16-41$ years of experience $(n=132)$. The mean age was 42.1 years $(\mathrm{SD}=9.95)$, ranging from 23 to 64 years. The mean work experience was 13.4 years $(\mathrm{SD}=$ 10.78), ranging from 0 to 41 years. All participants had gone through mandatory basic prehospital command and control joint training for both AIC and MIC organised by the ambulance organisation. The performance indicators are used in this training and also in reallife situations in the county, that is, the specific tasks and time limits were known by the participants of the study.

\subsection{Data analyses}

Data was analysed using the statistical software Stata 14.0 except for the moderation analyses for which the custom dialog box PROCESS by Hayes (2013) was used with SPSS 22. In the moderation analyses all predictor variables were transformed using grand mean centring.

\subsection{Independent and dependent variables}

A factor analysis with orthogonal varimax rotation resulted in five factors, organisation, social identity, collective efficacy, independence and relational trust, explaining $54.4 \%$ of the variation. All items in the factor analysis used a 7 point Likert scale.

The first factor, organisation $(7$ items, alpha $=.877$ ), contains items relating to their immediate supervisor and how they perceive this relationship, but also relating to the working conditions and resources in the organisation. Example items are: "I have great confidence in my immediate supervisor" and "There is a very open climate at work where we can discuss all possible work-related problems" (for a complete set of questions used in the study contact the corresponding author). High values represent a well-functioning organisation and relationship to the immediate supervisor.

The second factor, social identity ( 6 items, alpha $=.802)$, contains the aspects of the theoretical concept specified by Leach et al. (2008): group-level self-investment, including feelings of solidarity, satisfaction and centrality of the identity, as well as group-level selfdefinition mainly covered by expressions of self-stereotyping. Example items are: "I am committed to my work in the ambulance services" and "I am proud to belong to the ambulance services". High values represent stronger social identity and identification with the group.

The third factor, collective efficacy (6 items, alpha $=.744)$, involves items capturing a trust in and a belief that all working at the incident site together have all of the necessary resources and skills needed to solve any problems. Example items are: "I know that all of us from the ambulance services together always can solve even the most difficult tasks" and "I 
automatically trust colleagues from the ambulance". Theoretically this factor rests on Bandura's (1982) concept. High values represent a higher level of collective efficacy beliefs.

The fourth factor, independence $(4$ items, alpha $=.722$ ), captures aspects of independence when making decisions at an incident site - to not be affected by others, their expectations or what they will think about the decision. Example items are: "When I make a decision on an incident site I am almost never influenced by people from my own organisation" and "...I do not think about what others will think about the decision". It is in some ways a concept opposite the idea of accountability (Lerner \& Tetlock, 1999). High values represent higher independence in a decision situation.

Finally, the fifth factor, relational trust (4 items, alpha $=.713)$, involves a belief or position in how trust can be created. Example items are: "You have to earn trust" and "Trust can almost only be created through cooperation with others". High values on these factors represent a belief that trust has to be earned and something others have to prove by showing competence and skills, for example.

Professional confidence in the two roles were measured by two questions for each role: "In your role as ambulance/medical incident commander how well do you think you function?" and "In your role as ambulance/medical incident commander how confident are you?". Alpha for professional confidence in the roles as ambulance and medical incident commander were .888 and .892 respectively.

The performance indicators based on Rüter (2006), Rüter et al. (2004), Rüter and Vikström (2009), and Lundberg et al. (2008) used in this study were for the role of AIC how often they manage to (a) give a first report within two minutes, (b) take a decision on the guidelines for a response within three minutes and (c) give a second report from the incident site within 10 minutes from arrival. For MIC a single performance indicator was used. The question was how often they were able to decide on medical guidelines within 10 minutes from arrival at an incident site. All indicators were measured using a frequency scale from 'never' to 'always'.

\subsection{Ethical considerations}

All participants were informed about the purpose of the study before taking the survey; first in a separate email and then on the first page of the survey. They were informed that the survey was voluntary, that the responses would be treated confidentially and would be anonymised in all presentations, and that the data was to be used only for this research project. Overall approval for the study to be carried out was obtained via the R\&D manager for the Prehospital unit in the County who made sure information about the study was established through the heads of the units and down to each participant. It was through this channel we received email addresses once the study was anchored and approved within the organisations.

\section{Results}

\subsection{Professional confidence in the role}

There are two outcome variables in this study: professional confidence in the role of (a) Ambulance Incident Commander (AIC), and (b) Medical Incident Commander (MIC). In Table 1 descriptive statistics are presented. 
Table 1

Descriptive statistics for professional confidence in the roles

\begin{tabular}{llllll}
\hline Professional confidence in the role of & $\boldsymbol{n}$ & Mean & SD & Min & Max \\
\hline Ambulance Incident Commander & 304 & 5.26 & 1.14 & 1.5 & 7 \\
Medical Incident Commander & 252 & 5.55 & 1.00 & 2.5 & 7 \\
\hline
\end{tabular}

Men $($ mean $=5.41, S D=1.05)$ had greater professional confidence in the role of AIC, $t(301)$ $=-3.59, p<.001$, than women $($ mean $=4.91, S D=1.25)$. There was also a significant difference comparing EMTs (mean $=5.77, \mathrm{SD}=0.89)$ and ambulance nurses $($ mean $=4.98$, $S D=1.17), t(301)=6.056, p<.001$. For both the roles of AIC and MIC there were significant increases in professional confidence over time - a steady increase for AIC from one experience category to the next, $F(2,300)=14.76, p<.001$, and a significant increase from low to mid experience for MIC, but no further increase from mid to high experience, $F(2,248)=6.76, p=.001($ see Table 2$)$.

Table 2

Means and standard deviations for the factors, and $F$-values and $p$ for work experience

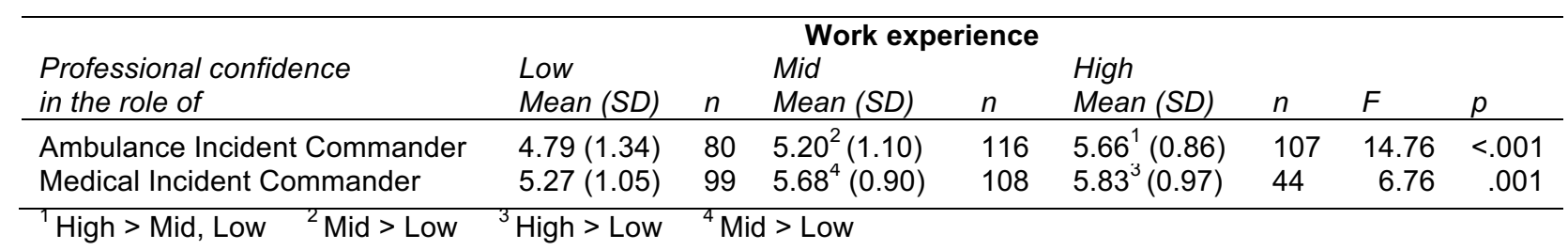

\subsection{Regression}

Hierarchical regression analyses have been conducted for both outcome variables, professional confidence in the roles ambulance and medical incident commander. Predictors were gender, occupation, work experience, organisation, social identity, collective efficacy, independence and relational trust.

\subsubsection{Ambulance Incident Commander}

In Table 3 a hierarchical regression analysis focussing on the role of AIC is presented. Work experience, organisation, collective efficacy and relational trust did not significantly contribute to the models and were excluded.

Table 3

Hierarchical regression on estimation of professional confidence in the role of Ambulance Incident Commander - regression coefficients ( $t$-values)

\begin{tabular}{lccc}
\hline & Model 1 & Model 2 & Model 3 \\
\hline Gender (Male) & $0.396(2.95)^{\star *}$ & $0.554(4.15)^{\star *}$ & $0.517(3.95)^{\star *}$ \\
Occupation (Nurse) & $-0.736(5.66)^{\star *}$ & $-0.500(3.72)^{\star *}$ & $-0.482(3.66)^{\star \star}$ \\
Social identity & & $0.333(4.85)^{\star *}$ & $0.307(4.56)^{\star *}$ \\
Independence & & & $0.171(3.73)^{\star *}$ \\
cons $_{R^{*}}$ & $5.463(37.01)^{\star *}$ & $3.303(7.07)^{\star *}$ & $2.814(5.91)^{\star *}$ \\
$N$ & 0.13 & 0.20 & 0.23 \\
$* p<0.05 ; * * p<0.01$ & 303 & 303 & 303
\end{tabular}

The analysis showed that both gender and occupation predict professional confidence - men and EMTs were more confident in the role of AIC. Adding social identity and also 
independence showed that regardless of gender and occupation, both help explain the variance of the professional confidence in the role, $F(4,298)=22.60, p<.001$.

Even though work experience didn't contribute significantly to the above model, it is related to professional confidence, $r(303)=.306, p<.001$. Analyses exploring possible moderating effects on this relationship were conducted (see Figure 1 for a schematic of moderating factors for the role of AIC). There were significant interactions between work experience and gender, $b=-0.037, S E B=0.019, t(302)=-1.982, p=.048$, and independence, $b=-0.008, S E B=0.004, t(302)=-2.216, p=.027$, on professional confidence in the role of AIC (see Figure 2). There was also a tendency for an interaction between work experience and occupation, $b=0.027, S E B=0.015, t(302)=1.802, p=.072$.

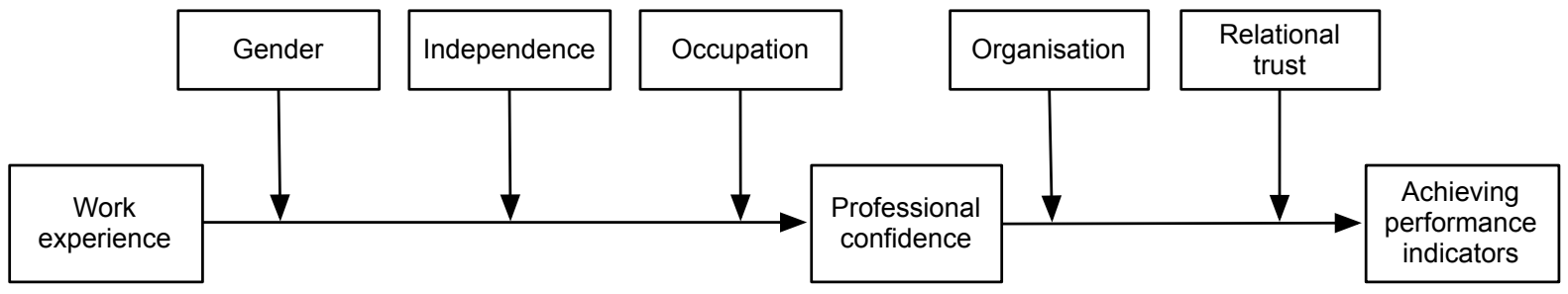

Figure 1. Schematic of moderating factors for professional confidence in the role of Ambulance Incident Commander and the ability to achieve performance indicators.
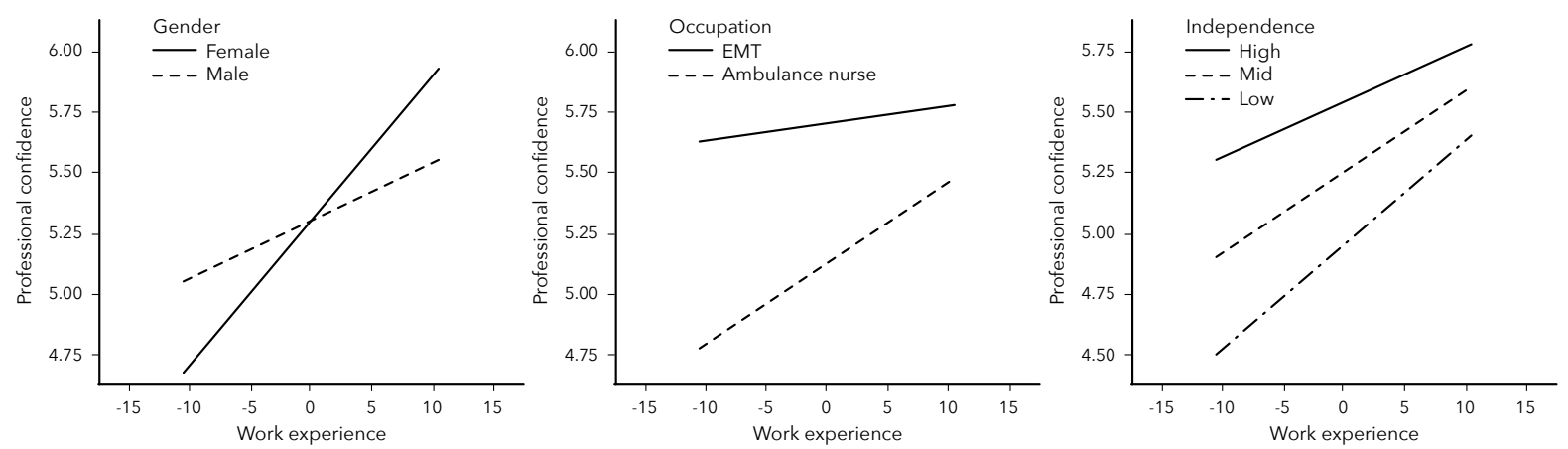

Figure 2. Moderators of work experience on professional confidence in the role of Ambulance Incident Commander.

Gender is a moderator for professional confidence in the role. For men there is only a small increase in confidence with increasing work experience. When starting to work in the ambulance service, men are more confident as AICs. For women the effects of work experience were a lot bigger. While starting off with a lower professional confidence, with time they surpassed the men. The moderating effects of occupation can be understood in terms of, for EMTs, no change in professional confidence over time, while ambulance nurses see an increase over time. They start off significantly lower than EMTs; however, highly experienced ambulance nurses still feel less confident compared to EMTs. The level of independence in a decision situation at an incident site is also a moderator. There is a clear difference in professional confidence in the role of AIC between levels of independence for those who have low work experience. This difference levels out with time.

Professional confidence in the role of AIC is also related to the ability to achieve the performance indicators, $r(304)=.372, p<.001$. In case of AIC the performance indicators are how often they manage to (a) give a first report (METHANE) within two minutes, (b) take a decision on the guidelines for a response within three minutes and (c) give a second report 
from the incident site within 10 minutes. Organisation, $b=-0.180, S E B=0.074, t(303)=-$ $2.421, p=.016$, and relational trust, $b=.226, S E B=0.107, t(303)=2.104, p=.036$, were moderators for this relationship (see Figure 3).
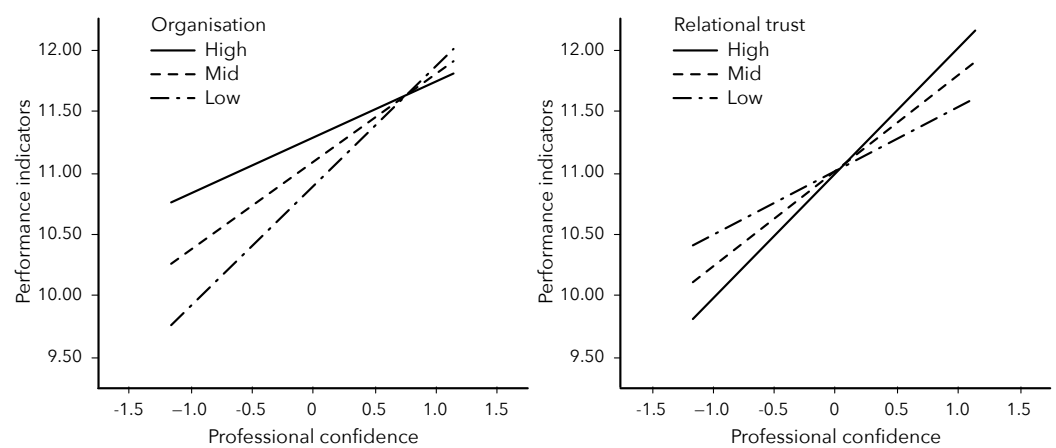

Figure 3. Moderators of professional confidence on ability to achieve performance indicators in the role of Ambulance Incident Commander.

Organisation is a moderator for the ability to achieve the performance indicators. Having high professional confidence in the role, there are no differences between having different levels of a well-functioning organisation and a good relationship to the immediate supervisor.

However, not feeling confident in the role, a well-functioning organisation can bolster the negative effects on performance achievement and can actually create conditions where the level of achievement is significantly improved. Also, relational trust, that is, a belief that trust has to be earned, is a moderator for performance indicator achievement. For high levels of professional confidence, high relational trust adds to performance indicator achievement, and the opposite is true for low levels.

\subsubsection{Medical Incident Commander}

In Table 4 a hierarchical regression analysis focussing on the role of MIC is presented. Gender, organisation, and collective efficacy did not significantly contribute to the models. Occupation was not included in the analysis at all because only nurses can be medical incident commanders.

Table 4

Hierarchical regression on estimation of professional confidence in the role of Medical Incident Commander - regression coefficients (t-values)

\begin{tabular}{lccc}
\hline & Model 1 & Model 2 & Model 3 \\
\hline Work experience & $0.031(3.91)^{\star *}$ & $0.030(3.87)^{\star *}$ & $0.035(4.69)^{\star *}$ \\
Social identity & & $0.222(3.20)^{\star *}$ & $0.188(2.84)^{\star *}$ \\
Independence & & & $0.159(3.29)^{\star *}$ \\
Relational trust & & & $0.193(3.87)^{\star *}$ \\
cons & $5.245(53.32)^{* *}$ & $4.011(10.10)^{\star *}$ & $2.677(5.89)^{\star *}$ \\
$R^{\alpha}$ & 0.06 & 0.10 & 0.19 \\
$N$ & 251 & 251 & 251 \\
\hline$p<0.05 ; * * p<0.01$ & & &
\end{tabular}

The analysis showed that work experience predicts professional confidence in the role of MIC. Adding social identity, and also independence and relational trust, showed that regardless of work experience all three help explain the variance of the professional confidence in the role, $F(4,246)=14.17, p<.001$. 
Work experience contributed significantly to the above model; it is related to professional confidence, $r(250)=.241, p<.001$. An analysis exploring possible moderating effects on this relationship was conducted (see Figure 4 for a schematic of moderating factors for the role of MIC). There was a significant interaction between work experience and social identity as a moderator on professional confidence in the role of MIC, $b=-0.021, S E B=0.009, t(250)=$ $2.341, p=.020$. The nurse's specialisation, as regular nurse, specialised in ambulance nursing or other specialisations (e.g. anaesthesia nursing), was also a moderator for this relationship, $b$ $=-0.041, S E B=0.011, t(250)=-3.568, p=.001$. Professional confidence is also related to the ability to achieve the performance indicators, $r(251)=.271, p<.001$. In case of MIC a performance indicator is how often they manage to make a decision on the medical guidelines for response within 10 minutes. Independence was a moderator for this relationship, $b=$ $0.122, S E B=0.056, t(251)=2.167, p=.031$ (see Figure 5).

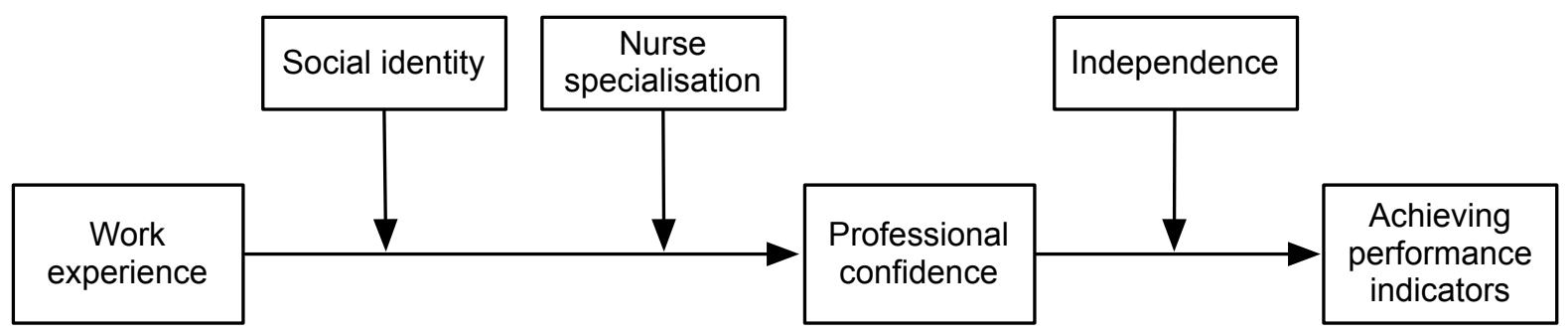

Figure 4. Schematic of moderating factors for professional confidence in the role of Medical Incident Commander and the ability to achieve performance indicators.
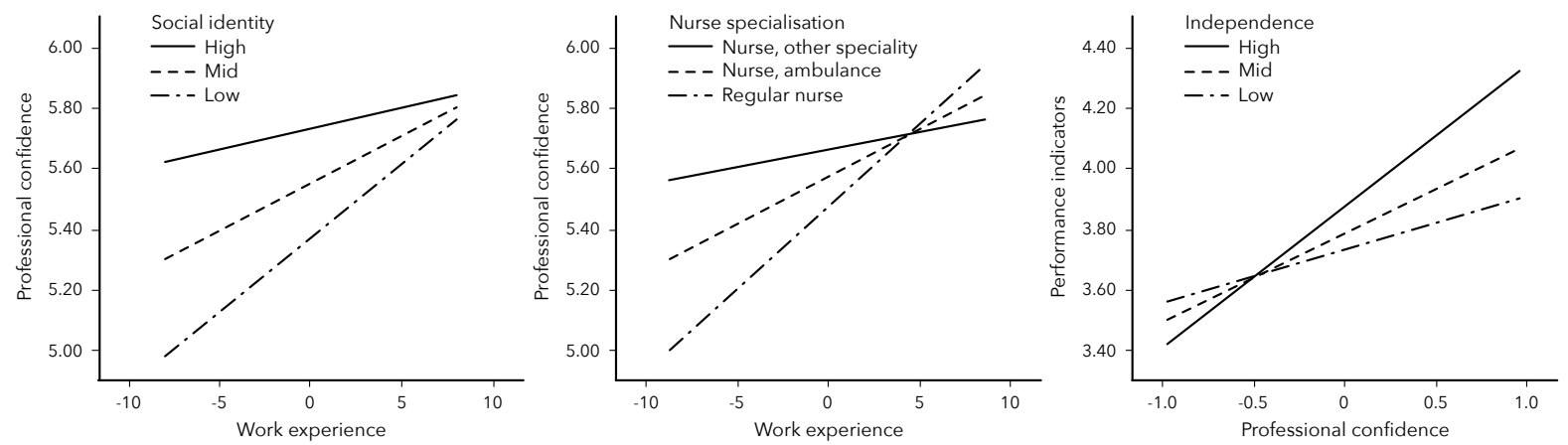

Figure 5. Social identity and nurse specialisation as moderators of work experience on confidence, and independence as moderator of professional confidence on ability to achieve performance indicators in the role of Medical Incident Commander.

Social identity is a moderator for professional confidence in the role of MIC. There are no effects for high work experience, but for low work experience a strong social identity can bolster confidence significantly. Also, the specialisation as a nurse moderates that relationship. Nurses with specialities other than ambulance nursing showed the highest professional confidence in the role of MIC when having a low work experience, while the regular nurses showed the lowest level. Those specialised in ambulance nursing came inbetween. With time the differences equal out. Independence in a decision situation at the incident site can improve the performance indicators for those with high professional confidence in the role, while independence has no or little effect for those with low confidence.

The main results are summarised and presented in Table 5. The table shows the predictors 
and moderators for professional confidence and performance in terms of achieved performance indicators for the two roles of AIC and MIC.

Table 5

Summary of the results. Variables predicting professional confidence and moderating confidence and performance (achieving performance indicators) for the roles of AIC and MIC

\begin{tabular}{|c|c|c|c|c|c|c|}
\hline & \multicolumn{3}{|c|}{ AIC } & \multicolumn{3}{|c|}{ MIC } \\
\hline & \multicolumn{2}{|c|}{$\begin{array}{l}\text { Professional } \\
\text { confidence }\end{array}$} & \multirow{2}{*}{$\begin{array}{c}\text { Performance } \\
\text { Moderator }\end{array}$} & \multicolumn{2}{|c|}{$\begin{array}{c}\text { Professional } \\
\text { confidence }\end{array}$} & \multirow{2}{*}{$\begin{array}{c}\text { Performance } \\
\text { Moderator }\end{array}$} \\
\hline & Predictor & Moderator & & Predictor & Moderator & \\
\hline Gender & $x$ & $x$ & & & & \\
\hline Work experience & & - & - & $x$ & - & - \\
\hline Occupation & $x$ & $x$ & & & & \\
\hline Nurse spec. & - & - & - & & $x$ & \\
\hline Social identity & $x$ & & & $x$ & $x$ & \\
\hline Independence & $x$ & $x$ & & $x$ & & $x$ \\
\hline Organisation & & & $x$ & & & \\
\hline Relational trust & & & $x$ & $x$ & & \\
\hline
\end{tabular}

\section{Discussion}

Professional confidence in the roles of ambulance and medical incident commander can be described as something that comes with experience. Those with high work experience are more confident in both roles; however, other factors play important roles when trying to understand how professional confidence in both roles develop.

\subsection{Ambulance Incident Commander}

For the role of AIC, gender, occupation, social identity (group identification) and independence in the decision-making influenced professional confidence in the role. Male EMTs identifying strongly with the group or profession and feeling independent in their decision-making have a higher professional confidence in the role. A strong identification with the group can bolster perceptions of collective efficacy and intragroup trust (Spears, 2010). Even though being alone in the role, a common social identity and through that also a possibility for heightened collective efficacy and intragroup trust can create a feeling of being part of a capable group and giving a sense of distributed responsibilities. The asymmetry in relation to police and rescue services (Berlin \& Carlström, 2011) as well as heterogeneity (Comfort, 2007) in the often uncertain situation at an incident site (Elmqvist et al., 2010; Rake \& Njå, 2009) can contribute to making a social identity salient and strengthen group identification.

Work experience can increase professional confidence, but more so for women, for ambulance nurses and for those less independent in decision-making situations. Work at incident sites is male dominated within the ambulance services as in all first responder organisations. This can involve overcoming cultural biases which could explain the lower initial degree of professional confidence on behalf of the women (Cech et al., 2012). Also, male attribution patterns have been shown to be more self-enhancing with higher levels of self-efficacy (Lloyd, Walsh \& Yailagh, 2005). This could indicate that an initial judgement when relatively new to the profession would be biased in favour of men. The requirement to include an ambulance nurse in all ambulances came 10 years ago in Sweden (Gårdelöv, 2016) and could probably still influence the perception of being someone from the outside destined 
to take over from the EMTs. The addition of a profession based on academic knowledge and with higher level of education becoming more and more common in the ambulance service, and in some ways beginning to phase out an entire profession (EMTs) may result in perceptions of less collegial support and with that less professional confidence in the role. If gender or occupation are salient social identities, women and ambulance nurses would be regarded as out-groups, resulting in reduced support and trust given in the situation (Haslam, 2004). Ambulance nurses also have greater responsibility compared to the EMTs and are to a higher degree required to work according to science and best practice. This could add to the initial lower degree of professional confidence among the nurses.

\subsection{Medical Incident Commander}

For the role of MIC, higher work experience, social identity (group identification), independence and relational trust positively influenced professional confidence in the role. Social identity moderated work experience on professional confidence where high social identity from the start almost could be seen as equal to the effects of high experience when looking at confidence. As pointed out earlier, a strong group identification can have strong positive effects on how one approaches one's tasks (Spears, 2010), as well as a stronger adherence to group norms (Livingstone et al., 2011). The response from the in-group could be a stronger support and trust given to the person being an MIC, even though he or she does not have much experience.

An interesting but unexpected finding was that nurse specialisation had an effect on professional confidence in the role of MIC for those with low experience. The unexpected result was that it was not those specialised as ambulance nurses that showed the highest level of professional confidence when relatively new in the occupation - it was those with other specialisations such as anaesthesia nurses. An explanation could be that those with other forms of specialisation probably have an identity and experience from, e.g. ICU or anaesthesiology to fall back on, whereas a regular nurse or a nurse with ambulance specialisation only have the ambulance as grounds for professional identity to fall back on an identity that still isn't perfectly clear within the ambulance organisation. The result also maybe says something about the educational effects a specialisation education can have. Many of the other specialisation educations, such as anaesthesia nursing, are possibly more prestigious and are regarded as more difficult than the ambulance specialisation education. This could be explained in terms of social identity (Haslam, 2004), where the salient identity for newly specialised nurses would be the specialisation rather than just a nurse. Others could also treat them differently, giving them stronger trust from the start based on the higher status of the specialisation facilitating communication (de Jong \& Elfring, 2010).

\subsection{Performance indicators}

For the AIC, the ability to give a first report, deciding on guidelines for the response, and to give a second report within the required time, was related to the level of professional confidence in the role. However, depending on the support felt from the immediate supervisor and the organisation, as well as the nature of trust given to others, this relationship looks different. With low levels of professional confidence together with low support from the organisation, the ability to manage the performance indicators suffers. On the other hand, a strong felt support from the immediate supervisor and the organisation boosts the performance indicators for those less confident almost to the level of those high in professional confidence. This shows the importance of being part of a supportive organisation and of having a working relationship with colleagues for professional confidence to develop (Holland et al., 2012). Feeling support from the organisation can strengthen identification 
with the group and also the collective efficacy (Spears, 2010). Perceived collective efficacy influences effort and staying power (Bandura, 1982) and could help in achieving the performance indicators in time. To require that others earn trust and at the same time having low levels of professional confidence in the role reduces the ability to reach the performance indicators in time. Building trust on personal experiences of behaviour rather than from joint group membership involves judging each new co-worker instead of trusting based on a common social identity (Haslam, 2004). There are probably pros and cons with this approach, but as many of the actions at an incident site depend on time, trust based on a social identity would probably make for swifter decisions.

A performance indicator for a MIC is to decide on medical guidelines within 10 minutes. This indicator was related to the level of professional confidence in the role and moderated by the level of independence. High independence in the decision situation and high professional confidence boost the performance indicator. Independence can be seen as the opposite to accountability (Lerner \& Tetlock, 1999). Accountability in relation to some actors at an incident site, such as the patients, is probably a good thing; however, in general, a sense of independence in a decision-making situation, relying on one's own knowledge and competence, would at least help in achieving the performance indicators in time. However, just achieving a performance indicator without knowing the correctness of the decision is not saying much about the action.

In line with Bandura's (1997) efficacy concept and the Dunning-Kruger effect (Dunning, 2011) a competent person assessing a clearly defined and well-known task would achieve higher accuracy comparing self-assessed performance and actual performance. The performance indicators used to assess performance in this study are well-known to the participants and the task involves activities they perform on a regular basis. Although the competence of the participants varies no one is ignorant of the tasks at hand when arriving at an incident site and the responsibilities connected to the particular role they have.

Training is an essential part in ensuring effective prehospital command and control at an incident site. Growing evidence support the use of simulation based training and team training to enhance clinical performance, confidence and self-efficacy (e.g. Watters et al., 2015; Wilkerson et al., 2008). Incorporating the results from this study in training, for example, the importance of identifying with the group, relational trust as well as clarity in the organization as a support would help developing professional confidence. Team training could also boost the collective efficacy beliefs within the organisation (Bandura, 1982) further strengthening the ability to handle incidents in the best possible way.

\subsection{Limitations}

Even though the study is based on a rather large sample, we had no control over who chose to answer it in the end. It is also only data from one county in one country in Europe. We have, however, no reason to assume there would be any large systematic bias in the sample, as the questions in the survey were not sensitive and were oriented toward the profession and not personal life. The second part of the aim, achievement of performance indicators, is based on self-assessed performance. As been discussed this assessment could be somewhat biased and the connection to actual performance cannot be established based on the current data. However, the participants are skilled and the concept of performance indicators is well-known to them ensuring a better fit between self-assessed and actual performance. Also, the most important result relating to this relationship is not on the relationship per se, but on the moderating factors. 


\section{Conclusion}

Professional confidence in the roles of ambulance and medical incident commander affect important tasks in the prehospital command related to performance indicators and thus patient care. These social psychological factors should probably be introduced more clearly in quality improvement programmes.

Finding ways to induce a social identity involving strong identification with working at the ambulance early on in the career can boost professional confidence in the role of medical incident commander. The effect of this for those new to the occupation is almost equal to having much working experience. If having high professional confidence an independent approach to decision-making situations can further improve the performance indicators. A degree of modesty in one's self-confidence could probably help in a decision-making situation, but as time is of the essence in decision-making at an incident site, too much reliance on others will hamper the process.

For the role of ambulance incident commander, an important aspect to consider is the lower professional confidence found in women new to the occupation. Women in a male dominated situation require extra consideration and support when new to the occupation. Of importance is also to focus on the effects a well-functioning organisation and especially the relation to the immediate supervisor can have on performance indicators for all.

\section{References}

Artologik (2015), Survey\&Report, http://www.artologik.com/en/SurveyandReport.aspx (accessed 22 September 2015).

Aylwin, C.J., König, T.C., Brennan, N.W., Shirley, P.J., Davies, G., Walsh, M.S. and Brohi, K. (2006), 'Reduction in Critical Mortality in Urban Mass Casualty Incidents: Analysis of Triage, Surge, and Resource Use After the London Bombings on July 7, 2005', The Lancet, Volume 368, Number 9554, pp. 2219-2225.

Bandura, A. (1982), 'Self-efficacy Mechanism in Human Agency', American Psychologist, Volume 37, Number 2, pp. 122-147.

Bandura, A. (1997), Self-efficacy: the exercise of control, Freeman, New York.

Berlin, J.M. and Carlström, E.D. (2011), 'Why is Collaboration Minimised at the Accident Scene?: A Critical Study of a Hidden Phenomenon', Disaster Prevention and Management, Volume 20, Number 2, pp. 159-171.

Bolling, R., Ehrlin, Y., Forsberg, R., Rüter, A., Soest, V. and Vikström, T. (2007), 'KAMEDO Report 90: Terrorist Attacks in Madrid, Spain, 2004', Prehospital and Disaster Medicine, Volume 22, Number 3, pp. 252-257.

Cech, E., Rubineau, B., Silbey, S., and Seron, C. (2011), 'Professional Role Confidence and Gendered Persistence in Engineering', American Sociological Review, Volume 76, Number 5, pp. 641-666. 
Comfort, L.K. (2007), 'Crisis Management in Hindsight: Cognition, Communication, Coordination, and Control', Public Administration Review, Volume 67, Number Supplement s1, pp. 189-197.

Cronin, P. and Reicher, S. (2009), 'Accountability Processes and Group Dynamics: A SIDE Perspective on the Policing of an Anti-Capitalist Riot', European Journal of Social Psychology, Volume 39, Number 2, pp. 237-254.

de Jong, B.A. and Elfring, T. (2010), 'How Does Trust Affect the Performance of Ongoing Teams? The Mediating Role of Reflexivity, Monitoring, and Effort', Academy of Management Journal, Volume 53, Number 3, pp. 535-549.

Dolan, B. and Holt, L. (2013), Accident \& Emergency, Theory into Practice (3rd edition), Bailliere Tindall, Kent.

Dreyfus, H.L. and Dreyfus, S.E. (1986), Mind Over Machine: The Power of Human Expertise and Intuition in the Era of the Computer, Free Press, New York.

Dunning, D. (2011), 'The Dunning-Kruger Effect: On Being Ignorant of One's Own Ignorance', Advances in Experimental Social Psychology, Volume 44, pp. 247-296.

Elmqvist, C., Brunt, D., Fridlund, B. and Ekebergh, M. (2010), 'Being First on the Scene of an Accident - Experiences of 'Doing' Prehospital Emergency Care', Scandinavian Journal of Caring Sciences, Volume 24, Number 2, pp. 266-273.

Ehrlinger, J. and Dunning, D. (2003), 'How chronic self-views influence (and potentially mislead) estimates of performance'. Journal of Personality and Social Psychology, Volume 84, Number 1, pp. 5-17.

Haslam, S.A. (2004), Psychology in Organizations: A Social Identity Approach, Sage, London.

Hayes, A.F. (2013), Introduction to Mediation, Moderation, and Conditional Process Analysis: A Regression-Based Approach, Guildford Press, New York.

Holland, K., Middleton, L. and Uys, L. (2012), 'Professional confidence: A concept analysis', Scandinavian Journal of Occupational Therapy, Volume 19, Number 2, pp. 214-224.

Gryth, D., Rådestad, M., Nilsson, H., Nerf, O., Svensson, L., Castrén, M. and Rüter, A. (2010), 'Evaluation of Medical Command and Control Using Performance Indicators in a Full-Scale, Major Aircraft Accident Exercise', Prehospital and Disaster Medicine, Volume 25, Number 2, pp. 118-123.

Gårdelöv, B. (2016), 'Ambulanssjukvårdens utveckling i Sverige', in Suserud, B.O. and Lundberg, L. (Eds.), Prehospital Akutsjukvård (2 ${ }^{\text {nd }}$ edition), Liber, Stockholm, pp. 40-47.

Johnson, D., Johnson, R. and Smith, K. (2007), 'The State of Cooperative Learning in Postsecondary and Professional Settings', Educational Psychology Review, Volume 19, Number 1, pp. 15-29. 
Juffermans, J. and Bierens, J. (2010), 'Recurrent Medical Response Problems During Five Recent Disasters in the Netherlands', Prehospital and Disaster Medicine, Volume 25, Number 2, pp.127-136.

Kroon, M., van Kreveld, D. and Rabbie, J. (1991), 'Police Intervention in Riots: The Role of Accountability and Group Norms. A Field Experiment', Journal of Community \& Applied Social Psychology, Volume 1, Number 4, pp. 249-267.

Leach, C.W., van Zomeren, M., Zebel, S., Vliek, M.L.W., Pennekamp, S.F., Doosje, B., Ouwerkerk, J.W. and Spears, R. (2008), 'Group-Level Self-Definition and Self-Investment: A Hierarchical (Multicomponent) Model of In-Group Identification', Journal of Personality and Social Psychology, Volume 95, Number 1, pp. 144-165.

Lennquist, S. (Ed) (2012), Medical Response to Major Incidents and Disasters, SpringerVerlag, Berlin.

Lerner, J.S. and Tetlock, P.E. (1999), 'Accounting for the Effects of Accountability', Psychological Bulletin, Volume 125, Number 2, pp. 255-275.

Livingstone, A.G., Haslam, S.A., Postmes, T. and Jetten, J. (2011), "We Are, Therefore We Should": Evidence that In-Group Identification Mediates the Acquisition of In-Group Norms', Journal of Applied Social Psychology, Volume 41, Number 8, pp. 1857-1876.

Lloyd, J.E.V., Walsh, J. and Yailagh, M. S. (2005), 'Sex Differences in Performance Attributions, Self-Efficacy, and Achievement in Mathematics: If I'm so Smart, Why Don't I Know It?', Canadian Journal of Education, Volume 28, Number 3, pp. 384-408.

Lundberg, L., Jonsson, A., Vikström, T. and Rüters, A. (2008), 'Performance Indicators for Prehospital Command and Control Developed for Civilian Use Tested in a Military Training Setting, a Pilot Study', Journal of the Royal Army Medical Corps, Volume 154, Number 4, pp. 236-238.

Nilsson, H. and Kristiansson, T. (2015), Katastrofmedicinsk beredskap - att leda sjukvård på ett särskilt sätt, Studentlitteratur, Lund.

Nilsson, H., Vikström, T. and Jonson, C.O. (2012), 'Performance Indicators for Initial Regional Medical Response to Major Incidents: A Possible Quality Control Tool', Scandinavian Journal of Trauma, Resuscitation and Emergency Medicine, Volume 20:81, http://www.sjtrem.com/content/20/1/81.

Ortiz, J. (2016), 'New graduate nurses' experiences about lack of professional confidence', Nurse Education in Practice, Volume 19, pp. 19-24.

Perry, P. (2011), 'Concept analysis: confidence/self-confidence', Nursing Forum, Volume 46, Number 4, pp. 218-230.

Rake, E.L. and Njå, O. (2009), 'Perceptions and Performances of Experienced Incident Commanders', Journal of Risk Research, Volume 12, Number 5, pp. 665-685. 
Rimstad, R. and Braut, G.S. (2015), 'Literature Review on Medical Incident Command', Prehospital and Disaster Medicine, Volume 30, Number 2, pp. 205-215.

Rogers, P. and Lea, M. (2011), 'Side-View: A Social Identity Account of ComputerSupported Collaborative Learning', Cyberpsychology, Volume 5, Number 2, Article 1. http://cyberpsychology.eu/view.php?cisloclanku=2011121701\&article=1.

Rüter, A. (2006), Disaster medicine - performance indicators, information support and documentation. A study of an evaluation tool, Linköping University Medical Dissertations No. 972, Linköping University, Sweden.

Rüter, A. and Vikström, A. (2009), 'Performance Indicators - From Theory to Implementation: One Method of Scientific Approach to Disaster Medicine', Urgence Pratique, Volume 93, pp. 41-44.

Rüter, A., Örtenwall, P. and Vikström T. (2004), 'Performance Indicators for Major Medical Management - A Possible Tool for Quality Control', International Journal of Disaster Medicine, Volume 2, Number 1-2, pp. 52-55.

Rüter, A., Örtenwall, P. and Vikström, T. (2007), 'Staff Procedure Skills in Management Groups During Exercises in Disaster Medicine', Prehospital and Disaster Medicine, Volume 22, Number 4, pp. 318-21.

Sani, F. (2012), 'Group Identification, Social Relationships, and Health', in Jetten, J., Haslam, C. and Haslam, S.A. (Eds.), The Social Cure, Psychology Press, Hove, pp. 21-37.

Scholten, L., van Knippenberg, D., Nijstad, B.A. and de Dreu, C.K.W. (2007), 'Motivated Information Processing and Group Decision-Making: Effects of Process Accountability on Information Processing and Decision Quality', Journal of Experimental Social Psychology, Volume 43, Number 4, pp. 539-552.

Simons, T.L. and Peterson, R.S. (2000), 'Task Conflict and Relationship Conflict in Top Management Teams: The Pivotal Role of Intragroup Trust', Journal of Applied Psychology, Volume 85, Number 1, pp. 102-111.

Smith, S., Farra, S., Dempsey, A. and Arms, D. (2015), 'Preparing Nursing Students for Leadership Using a Disaster-Related Simulation', Nurse Educator, Volume 40, Number 4, pp. 212-216.

Sollid, S.J.M., Rimstad, R., Rehn, M., Nakstad, A.R., Tomlinson, A.E., Strand, T., Heimdal, H.J., Nilsen, J.E. and Sandberg, M. (2012), 'Oslo Government District Bombing and Utøya Island Shooting July 22, 2011: The Immediate Prehospital Emergency Medical Service Response', Scandinavian Journal of Trauma, Resuscitation and Emergency Medicine, Volume 20, Number 1, 3. http://doi.org/10.1186/1757-7241-20-3.

Spears, R. (2010), 'Group Rationale, Collective Sense: Beyond Intergroup Bias', British Journal of Social Psychology, Volume 49, Number 1, pp. 1-20.

Stajkovic, A.D. and Luthans, F. (1998), Self-efficacy and work-related performance: A metaanalysis. Psychological Bulletin, Volume 124, Number 2, pp. 240-261. 
Suserud, B.O. (2005), 'A New Profession in the Pre-Hospital Care Field--The Ambulance Nurse', Nursing in Critical Care, Volume 10, Number 6, pp. 269-271.

Suserud, B.O. and Haljamäe, H. (1997), 'Role of Nurses in Pre-Hospital Emergency Care', Accident and Emergency Nursing, Volume 5, Number 3, pp. 145-151.

Tajfel, H. and Turner, J.C. (1979), 'An Integrative Theory of Intergroup Conflict', in Worchel, S. and Austin, W.G. (Eds), The Psychology of Intergroup Relations, Brooks-Cole, Monterey, CA, pp. 33-47.

The National Board of Health and Welfare. (2000), National Board regulations and general guidelines of drugs in health care (in Swedish: Socialstyrelsens föreskrifter och allmänna råd om läkemedelshantering i hälso- och sjukvården), SOSFS 2000:1.

The National Board of Health and Welfare. (2005), Peacetime disaster medical preparedness and planning ahead of heightened alert (in Swedish: Fredstida katastrofmedicinsk beredskap och planläggning inför höjd beredskap), SOSFS 2005:13.

The National Board of Health and Welfare. (2009), Ambulance care etc. (in Swedish: Ambulanssjukvård m.m.), SOSFS 2009:10.

The National Board of Health and Welfare. (2013), The National Board's regulations and general advice on disaster medical preparedness (in Swedish: Socialstyrelsens föreskrifter och allmänna råd om katastrofmedicinsk beredskap), SOSFS 2013:22.

Watters, C., Reedy, G., Ross, A., Morgan, N.J., Handslip, R. and Jaye, P. (2015), 'Does Interprofessional Simulation Increase Self-efficacy: A Comparative Study', BMJ Open, 5:e005472. doi:10.1136/bmjopen-2014-005472.

Wilkerson, W., Avstreih, D., Gruppen, L., Beier, K. P. and Woolliscroft, J. (2008). Using immersive simulation for training first responders for mass casualty incidents Academic Emergency Medicine, 15(11), 1152-1159. 